\title{
Systematic review of the relationships between sleep duration and health indicators in the early years (0-4 years)
}

Jean-Philippe Chaput ${ }^{*}$, Casey E. Gray ${ }^{1}$, Veronica J. Poitras ${ }^{1}$, Valerie Carson², Reut Gruber ${ }^{3}$, Catherine S. Birken ${ }^{4}$, Joanna E. MacLean ${ }^{5}$, Salomé Aubert ${ }^{1}$, Margaret Sampson $^{1}$ and Mark S. Tremblay ${ }^{1}$

\begin{abstract}
Background: The objective of this systematic review was to examine for the first time the associations between sleep duration and a broad range of health indicators in children aged 0 to 4 years.

Methods: Electronic databases were searched with no limits on date or study design. Included studies (published in English or French) were peer-reviewed and met the a priori determined population (apparently healthy children aged 1 month to 4.99 years), intervention/exposure/comparator (various sleep durations), and outcome criteria (adiposity, emotional regulation, cognitive development, motor development, growth, cardiometabolic health, sedentary behaviour, physical activity, quality of life/well-being, and risks/injuries). The quality of evidence was assessed using the Grading of Recommendations Assessment, Development and Evaluation (GRADE) framework. Due to high levels of heterogeneity across studies, narrative syntheses were employed.
\end{abstract}

Results: A total of 69 articles/studies (62 unique samples) met inclusion criteria. Data across studies included 148,524 unique participants from 23 countries. The study designs were randomized trials $(n=3)$, non-randomized interventions $(n=1)$, longitudinal studies $(n=16)$, cross-sectional studies $(n=42)$, or longitudinal studies that also reported cross-sectional analyses $(n=7)$. Sleep duration was assessed by parental report in $70 \%$ of studies $(n=48)$ and was measured objectively (or both objectively and subjectively) in 30\% of studies $(n=21)$. Overall, shorter sleep duration was associated with higher adiposity (20/31 studies), poorer emotional regulation (13/25 studies), impaired growth ( $2 / 2$ studies), more screen time (5/5 studies), and higher risk of injuries ( $2 / 3$ studies). The evidence related to cognitive development, motor development, physical activity, and quality of life/well-being was less clear, with no indicator showing consistent associations. No studies examined the association between sleep duration and cardiometabolic biomarkers in children aged 0 to 4 years. The quality of evidence ranged from "very low" to "high" across study designs and health indicators.

Conclusions: Despite important limitations in the available evidence, longer sleep duration was generally associated with better body composition, emotional regulation, and growth in children aged 0 to 4 years. Shorter sleep duration was also associated with longer screen time use and more injuries. Better-quality studies with stronger research designs that can provide information on dose-response relationships are needed to inform contemporary sleep duration recommendations.

Keywords: Adiposity, Emotional regulation, Cognitive development, Motor development, Growth, Cardiometabolic health, Physical activity, Sedentary behaviour, Quality of life, Well-being, Injuries, Newborns, Infants, Toddlers, Preschoolers

\footnotetext{
* Correspondence: jpchaput@cheo.on.ca

${ }^{1}$ Healthy Active Living and Obesity Research Group, Children's Hospital of Eastern Ontario Research Institute, 401 Smyth Road, Ottawa, ON K1H 8L1, Canada

Full list of author information is available at the end of the article
} 


\section{Background}

Sleep is essential for healthy cognitive, psychosocial, and physical health $[1,2]$. Healthy sleep is generally defined by adequate duration, appropriate timing, good quality, and the absence of sleep disturbances or disorders [3]. Sleepwake regulation and sleep states evolve rapidly during the first year of life, with continued maturation across childhood [4]. For example, newborns ( $0-3$ months) do not have an established circadian rhythm [5]; this begins to emerge at around 10-12 weeks of age, with sleep becoming more nocturnal between ages 4-12 months [6]. Children continue to take daytime naps between 1 and 4 years of age, and night wakings are common in infancy and early childhood [7]. By age 5, daytime napping typically ceases and overnight sleep duration gradually declines throughout childhood, in part due to a shift to later bedtimes and unchanged wake times [7].

Sleep patterns can vary between individuals and are explained by a complex interplay between genetic, environmental, behavioural, and social factors. For example, factors such as parenting practices and expectations, family routines, cultural preferences, and daycare schedules can all influence sleep [4]. Findings from a recent systematic review of 69,542 infants, toddlers, and preschoolers from 18 countries showed mean reference values and ranges $( \pm 1.96 \mathrm{SD})$ of $12.8 \mathrm{~h} /$ day $(9.7-15.9)$ for infants (<2 years), and $11.9 \mathrm{~h} /$ day $(9.9-13.8)$ for toddlers/preschoolers (ages 2-5 years) [8]. These international normative data can help to determine the normative distribution of sleep duration, but cannot identify duration associated with health benefits.

Although many studies have confirmed the importance of sleep duration for individual health outcomes, to our knowledge no study has attempted to systematically and comprehensively examine the literature on the associations between sleep duration and a broad range of health indicators in children aged 0-4 years. A systematic review can help to determine whether the available evidence supports existing sleep duration recommendations. The National Sleep Foundation recommends that for every 24-h cycle, newborns (0-3 months) obtain 14-17 h of sleep, infants (4-11 months) obtain $12-15 \mathrm{~h}$ of sleep, toddlers (1-2 years) obtain $11-14 \mathrm{~h}$ of sleep, and preschoolers (3-5 years) obtain $10-13 \mathrm{~h}$ of sleep [9]. Similarly, the American Academy of Sleep Medicine recommends that infants (4-11 months) sleep $12-16 \mathrm{~h} /$ day, children 1 to 2 years of age sleep 11-14 h/ day, and children 3 to 5 years of age sleep 10-13 h/day on a regular basis (including naps) to promote optimal health [10]. Although the ideal amount of sleep may vary from one person to another, sleep duration recommendations are important for surveillance and to inform public policies, interventions, and the general public of healthy sleep behaviours $[11,12]$.
Therefore, the present work aims to provide a global picture of how sleep duration relates to, or affects, a broad set of health indicators in children aged 0-4 years, and findings from this review will help to better inform sleep duration recommendations for this population and identify future research needs. More specifically, the objective of this systematic review is to examine the relationships between sleep duration and various health indicators in children aged $0-4$ years.

\section{Methods}

\section{Protocol and registration}

This review was registered a priori with the International Prospective Register of Systematic Reviews (PROSPERO; Registration no. CRD42016040096; available from http://www.crd.york.ac.uk/PROSPERO/ display_record.asp?ID=CRD42016040096), and was conducted following the Preferred Reporting Items for Systematic Reviews and Meta-Analyses (PRISMA) statement for reporting systematic reviews and metaanalyses [13].

\section{Eligibility criteria}

The Participants, Interventions, Comparisons, Outcomes, and Study design (PICOS) framework [14] was followed to identify key study concepts in the research question a priori, and to facilitate the search process.

\section{Population}

The population included apparently healthy (i.e., general populations, including those with overweight/obesity, but with no diagnosed medical condition) children aged 1 month to 4.99 years for at least one exposure measurement point. Clinical populations (e.g., patients with sleep apnea) were excluded. Subgroups were defined as: newborns (0-3 months), infants (4-11 months), toddlers (1-2 years), and preschoolers (3-4.99 years).

\section{Intervention (exposure)}

The intervention or exposure was sleep duration. Studies were included if they used objective (e.g., polysomnography, actigraphy/accelerometry) or subjective (e.g., proxyreport) measures of sleep duration (or both). This could include actual sleep duration or even time in bed, depending on how it was reported in the studies. Experimental studies were included only if the intervention targeted sleep duration exclusively and not multiple health behaviours (e.g., interventions that targeted both sleep and diet).

\section{Comparison}

Various sleep durations were used for comparison. A comparator or control group was not required for inclusion. 


\section{Outcomes (health indicators)}

Ten health indicators were chosen based on the literature, expert input and consensus, and recognition of the importance of including a broad range of health indicators. Five health indicators were identified as critical (primary outcomes) by expert agreement: (1) adiposity (e.g., overweight, obesity, body mass index, skinfold thickness, body fat); (2) emotional regulation (e.g., mood, social-emotional problems, stress, hyperactivity/impulsivity); (3) cognitive development (e.g., learning, memory, attention, concentration, language development); (4) motor development (e.g., gross motor skills, fine motor skills, locomotor and object control); and (5) growth. Five health indicators were identified as important (secondary outcomes) by expert agreement: (1) cardiometabolic health (e.g., blood pressure, blood lipids, glucose, insulin); (2) sedentary behaviour (e.g., screen time); (3) physical activity (e.g., moderate- to vigorous-intensity physical activity); (4) quality of life/well-being; and (5) risks/injuries.

\section{Study designs}

All study designs, except case studies, were eligible for inclusion in this systematic review. In longitudinal studies, any follow-up length was allowed; however, the exposure had to be assessed at least once during the identified age range. There were no sample size restrictions for studies included in this systematic review. Published peerreviewed original manuscripts and "in press" articles were eligible for inclusion, as were studies with results posted to a trial registry. Grey literature, book chapters, dissertations and conference abstracts were excluded.

\section{Information sources and search strategy}

A research librarian with expertise in systematic review searching created the electronic search strategy. A second research librarian peer-reviewed it. See Additional file 1: Table S1 for the complete search strategies. The following databases were searched using the Ovid interface, initially in June and again in November 2016: MEDLINE (1946 to November 1, 2016), EMBASE (1980 to 2016 Week 44), PsychINFO (1806 to 2016 October Week 4), and the Cochrane Central Register of Controlled Trials (CENTRAL) (September 2016). Trial registries (https://clinical trials.gov and http://who.int/ictrp/en) were searched for registered clinical trials that met our inclusion/exclusion criteria and where results were posted online. Reference lists of relevant reviews were also checked. Studies were included if they were published in English or French.

\section{Study selection}

References were extracted as text files and imported into the Reference Manager Software (Thompson Reuters,
San Francisco, CA, USA) for removal of duplicate references. Titles and abstracts of potentially relevant articles were imported to DistillerSR (Evidence Partners, Ottawa, ON, Canada), and were screened independently by two reviewers. Exclusion by both reviewers was needed for a study to be excluded at the first level screening. A fulltext copy of each article that met initial screening criteria was obtained, and the same two reviewers independently examined all full-text manuscripts (level 2 screening). Any discrepancies were resolved with a discussion and consensus between the two reviewers. If the reviewers were unable to reach consensus, a third reviewer was asked to examine the article.

\section{Data extraction}

Data extraction was completed in Excel (Microsoft) and checked for accuracy by a second reviewer. Results from the most fully adjusted models were extracted for studies that reported findings from multiple models. Important study features (i.e., author, publication year, study design, country, sample size, age and sex of participants, measure of sleep duration and health outcomes, results, and confounders) were extracted.

\section{Risk of bias and study quality assessment}

A risk of bias assessment was completed for all included studies, as described in the Cochrane Handbook [15]. Briefly, the risk of bias assessment identifies methodological features of each study that can impact confidence in the overall estimate of effect for an outcome. The quality of evidence for each outcome by type of study design was determined using the Grading of Recommendations Assessment, Development and Evaluation (GRADE) framework [16]. The GRADE framework categorizes the quality of evidence into four groups (high, moderate, low, and very low). The quality of evidence rating starts at "high" for randomized studies and at "low" for all other studies (e.g., non-randomized experiments or observational studies). The quality of evidence can be downgraded if there are serious limitations across studies (e.g., serious risk of bias, inconsistency of relative treatment effects, indirectness, imprecision, or other factors) [16]. The quality of evidence assessment was conducted by the lead author (J.-P. Chaput) and verified by the larger review team, including systematic review methodology experts (M. Sampson and A. Jaramillo). Disagreements were resolved by discussion among the team members, if needed.

\section{Synthesis of results}

A meta-analysis was planned in the event that findings were found to be sufficiently homogenous in terms of methodological, statistical, and clinical characteristics. If not sufficiently homogeneous, narrative syntheses were planned. 


\section{Results}

\section{Description of studies}

As shown in Fig. 1, a total of 1382 records were identified through database searches and an additional three unique records were identified through reference list searches and through the review team and collaborators. Trial registries did not yield any eligible studies. After removing duplicates, a total of 1154 records remained. After titles and abstracts were screened, 133 full-text articles were obtained for further review and 69 articles/studies met the inclusion criteria (from 62 unique samples). Reasons for excluding articles were: not reporting sleep duration as it relates to a health outcome $(n=23)$, no measure of sleep duration $(n=15)$, ineligible age $(n=10)$, participants not apparently healthy $(n=8)$, sleep duration was treated as a covariate or outcome only $(n=5)$, intervention not targeting sleep duration $(n=1)$, not with human participants $(n=1)$, and not original research (i.e., review paper) $(n=1)$. Some studies were excluded for multiple reasons.

Characteristics of studies sorted by outcome indicator are summarized in Additional file 2: Table S2. Data across studies involved 148,524 unique participants. Studies were conducted in 23 different countries from five continents (North America, South America, Europe, Australia/Oceania, and Asia); however, studies were predominantly from North America with White/ Caucasian ethnicity. Studies were published between 1992 and 2016, although most were published in the past 5 years. The study designs were randomized trials $(n=3)$, non-randomized interventions $(n=1)$, longitudinal studies $(n=16)$, cross-sectional studies $(n=42)$, or longitudinal studies that also reported crosssectional analyses $(n=7)$. Sleep duration was measured objectively (polysomnography or actigraphy/accelerometry) in 10 studies, subjectively (parent-report) in 48 studies, and by both actigraphy/accelerometry and a sleep log in 11 studies. It was determined by the review team that a meta-analysis was not possible because of high levels of heterogeneity across studies (see Additional file 2: Table S2), and narrative syntheses were employed instead. All studies are given equal weight in a narrative synthesis of the evidence.

\section{Data synthesis Adiposity}

A total of 31 studies examined the association between sleep duration and adiposity indicators (Table 1 and Additional file 2: Table S2). Among the 13 longitudinal studies, 10 reported that shorter sleep duration was associated with adiposity gain [17-26], 2 reported null findings [27, 28], and 1 reported that longer sleep duration predicted adiposity gain [29]. The quality of

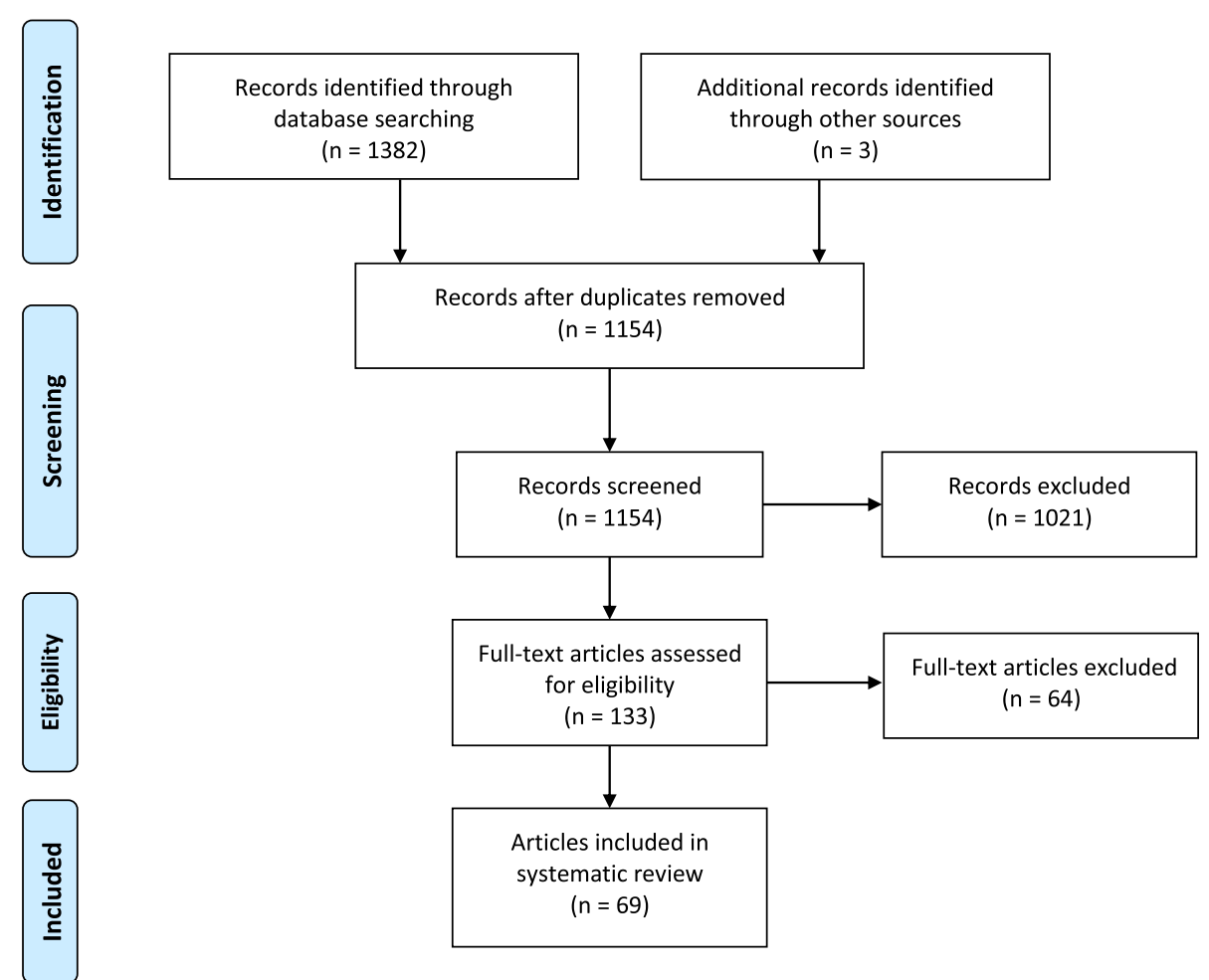

Fig. 1 PRISMA flow diagram for the identification, screening, eligibility, and inclusion of studies 


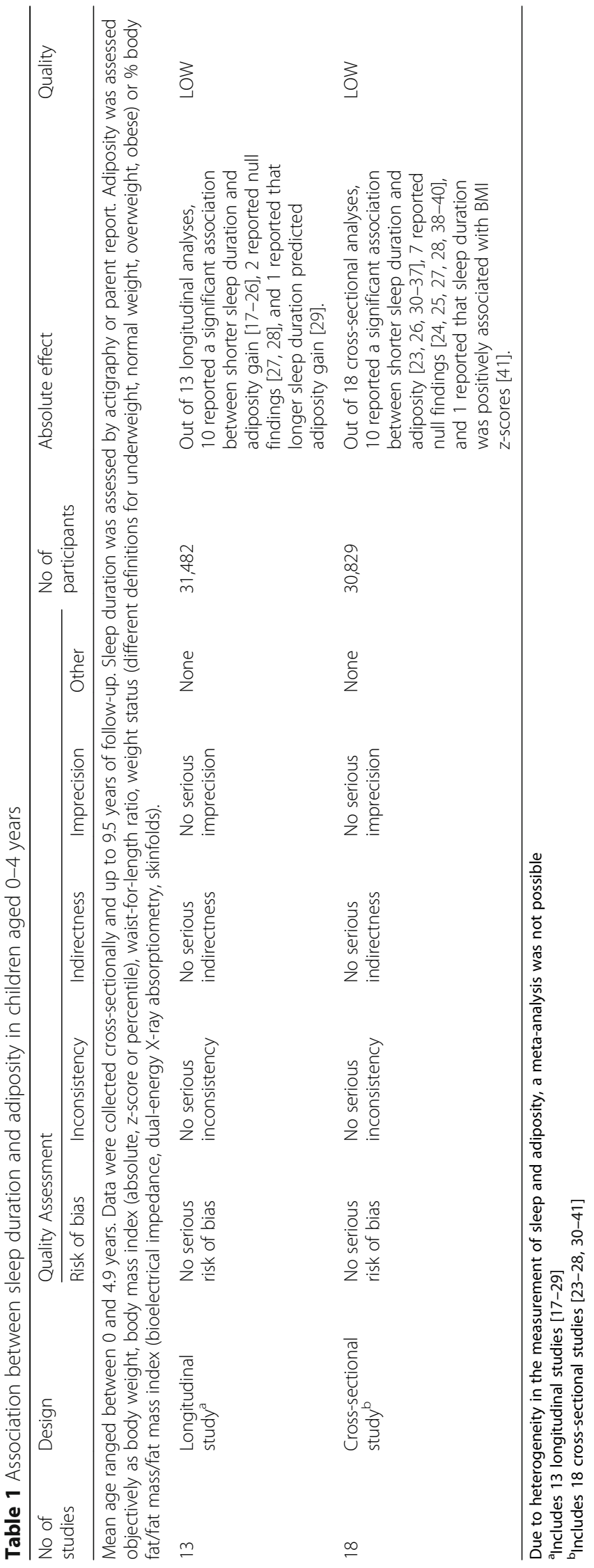


evidence remained at "low" for the longitudinal studies. Among the 18 cross-sectional studies, 10 reported a significant association between shorter sleep duration and adiposity [23, 26, 30-37], 7 reported null findings $[24,25,27,28,38-40]$, and 1 reported that sleep duration was unfavourably associated with adiposity [41]. The quality of evidence remained at "low" for the cross-sectional studies.

\section{Emotional regulation}

A total of 25 studies examined the association between sleep duration and emotional regulation (Table 2 and Additional file 2: Table S2). The 2 randomized studies (both randomized cross-over trials) showed better selfregulation strategies and emotional responses in the routine sleep versus the sleep restriction condition $[42,43]$. The quality of evidence remained at "high" for the randomized trials. There was also 1 non-randomized trial showing a reduced morning cortisol awakening response after sleep restriction [44]. The quality of evidence was downgraded from "low" to "very low" because of a serious risk of imprecision. Among the 5 longitudinal studies, 2 reported that shorter sleep duration was associated with poorer emotional regulation at follow-up $[45,46]$, while 3 reported null findings [47-49]. The quality of evidence remained at "low" for the longitudinal studies. Among the 17 cross-sectional studies, 8 reported that shorter sleep duration was associated with poorer emotional regulation [50-57], 7 reported null findings [38, 49, 58-62], and 2 reported opposite associations $[63,64]$. The quality of evidence was downgraded from "low" to "very low" due to a serious inconsistency in the findings.

\section{Cognitive development}

A total of 16 studies examined the association between sleep duration and cognitive development (Table 3 and Additional file 2: Table S2). One randomized trial examined this association [65] and found that the number of correct answers in an explicit recognition task was significantly higher in the nap condition compared to the wake (sleep restriction) condition; however, implicit memory (priming task) did not differ between conditions. The quality of evidence remained at "high" for this randomized trial. The 4 longitudinal studies that examined the relationships between sleep duration and cognitive development provided mixed findings, although they had mainly favourable associations or null findings [66-69]. The quality of evidence for longitudinal studies remained at "low". Finally, of 11 cross-sectional studies, 7 reported null findings [38, 51, 55, 70-73], 3 reported that shorter sleep duration was associated with poorer cognitive function [57, 74, 75], and 1 reported opposite associations [76]. The quality of evidence remained at "low" for the cross-sectional studies.

\section{Motor development}

Two cross-sectional studies examined the association between sleep duration and motor development (Table 4 and Additional file 2: Table S2). Both studies reported no associations between sleep duration, and gross and fine motor skills $[38,51]$. The quality of evidence remained at "low" for the cross-sectional studies.

\section{Growth}

Two studies examined the relationship between sleep duration and linear growth (Table 5 and Additional file 2: Table S2). The longitudinal study by Lampl et al. [29] showed that higher total daily sleep hours and number of sleep bouts were significantly associated with growth in infant length. The quality of evidence was downgraded from "low" to "very low" for this study because of a serious risk of bias. In the cross-sectional study [77], sleep was assessed both objectively and subjectively in 6month-old infants. The authors reported that shorter actigraphy-measured sleep duration was associated with higher weight-for-length ratio in girls only. The results also showed that, in the total sample, shorter night sleep duration (as reported by parents) was associated with higher weight-for-length ratio and weight above the expected weight for length. The quality of evidence was downgraded from "low" to "very low" due to a serious risk of imprecision.

\section{Cardiometabolic health}

No studies examined the association between sleep duration and cardiometabolic biomarkers in children aged $0-4$ years.

\section{Sedentary behaviour}

A total of 5 studies (1 longitudinal study and 4 crosssectional studies) examined the association between sleep duration and screen time (Table 6 and Additional file 2: Table S2). The longitudinal study showed that longer sleep duration at 4 years of age was associated with less television viewing and computer use at 6 years of age [22]. The quality of evidence was downgraded from "low" to "very low" due to a serious risk of bias. The 4 cross-sectional studies [31, 78-80] showed that shorter sleep duration was associated with more screen time. The quality of evidence was downgraded from "low" to "very low" because of a serious risk of bias.

\section{Physical activity}

Four studies (1 longitudinal study and 3 cross-sectional studies) examined the association between sleep duration and physical activity (Table 7 and Additional file 2: Table S2). The longitudinal study showed that sleep duration at 4 years of age was not associated with level of physical activity at 6 years of age [22]. The quality of 


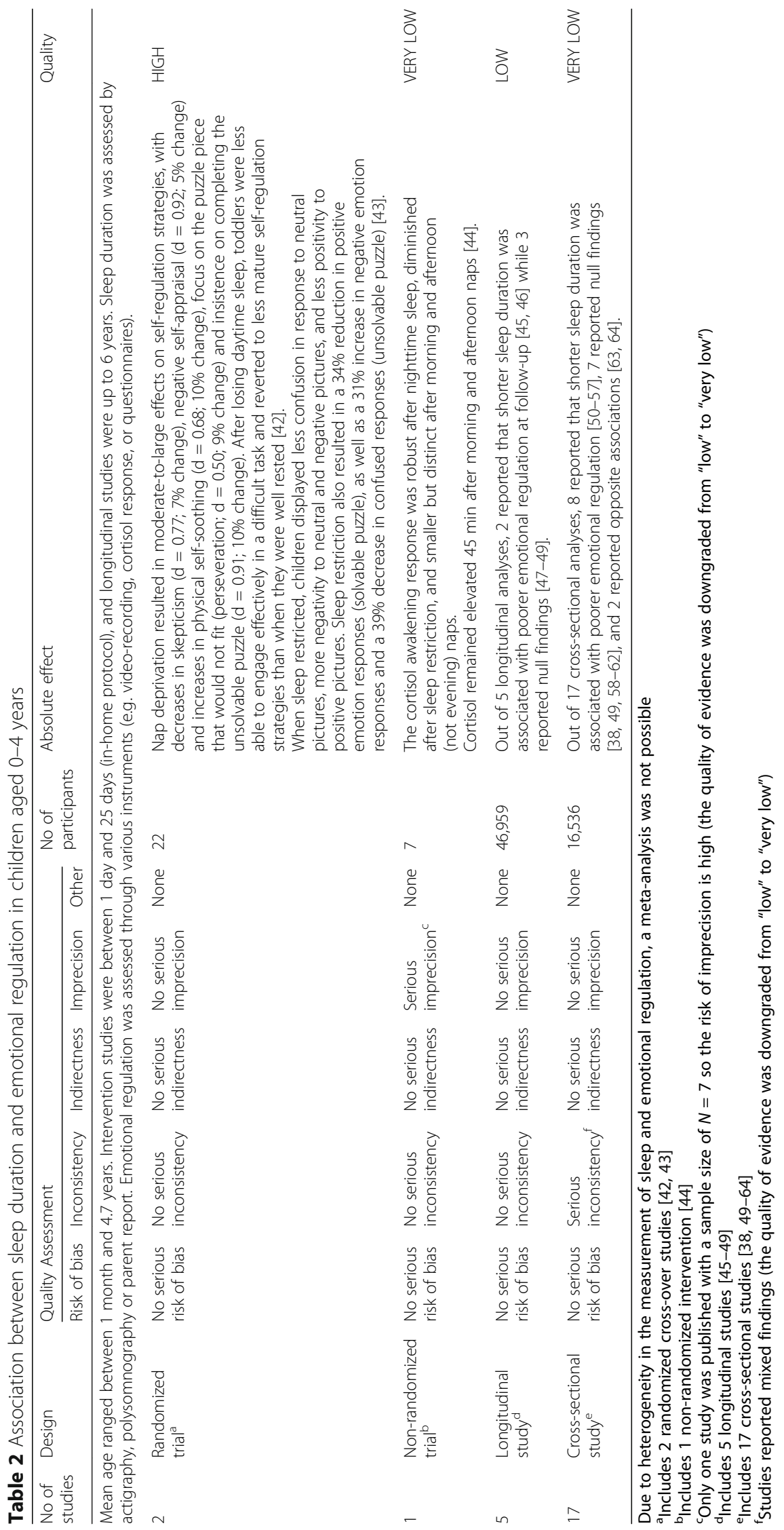




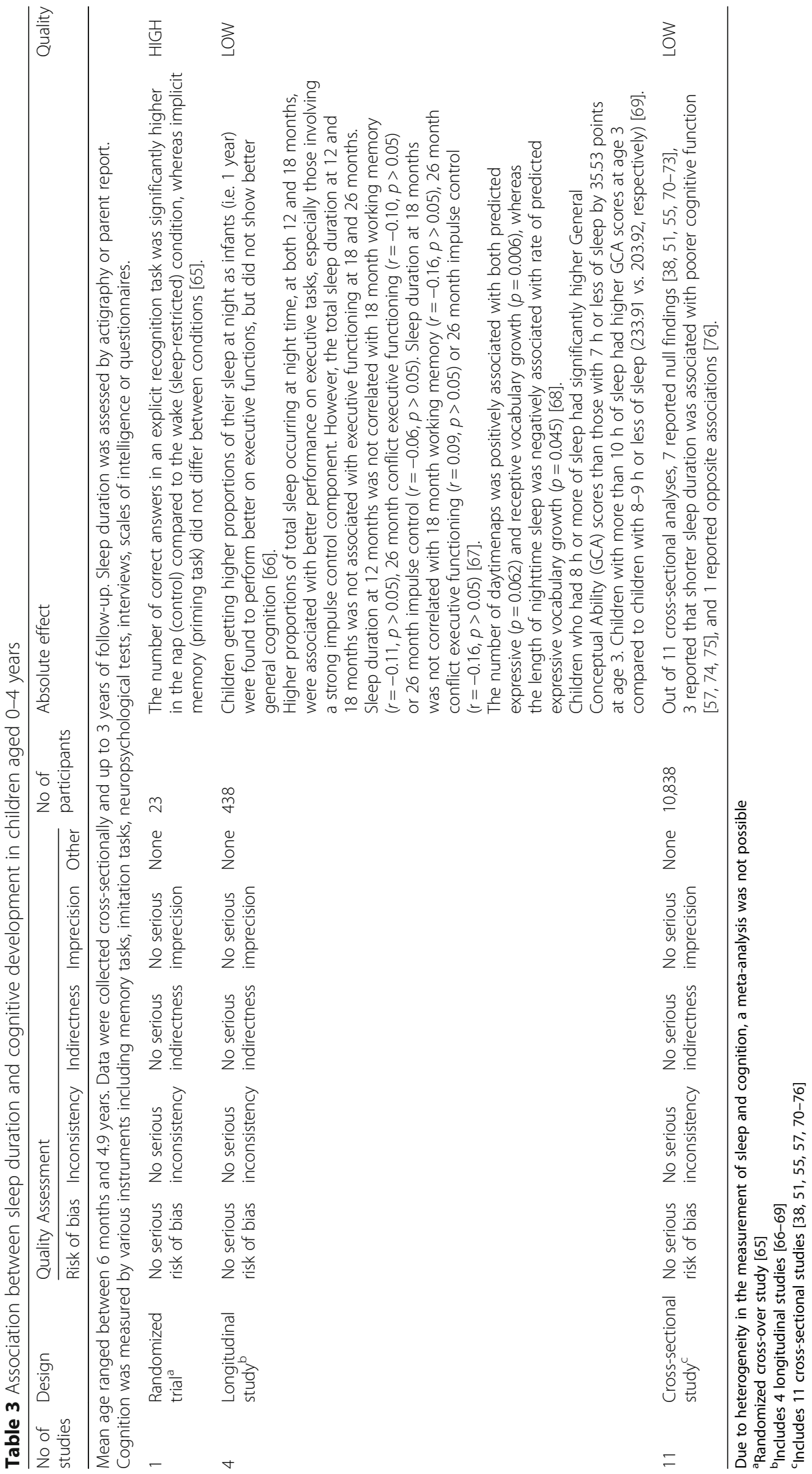


Table 4 Association between sleep duration and motor development in children aged 0-4 years

\begin{tabular}{llll}
\hline $\begin{array}{l}\text { No of } \\
\text { studies }\end{array}$ & Design & Quality Assessment & $\begin{array}{l}\text { No of } \\
\text { participants }\end{array}$
\end{tabular}

Mean age ranged between 7.4 months and 13 months. Data were collected cross-sectionally only. Sleep duration was assessed by actigraphy or parent report. Motor development was assessed using the Ages and Stages Questionnaire in both studies.

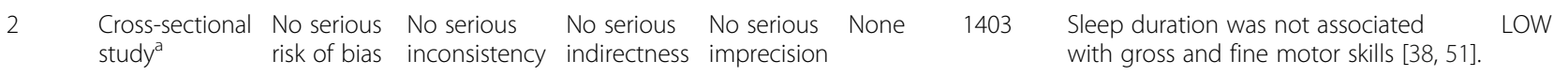

Due to the fact that only two studies were published on sleep duration and motor development (with different methodologies and age groups),

a meta-analysis was not possible

ancludes 2 cross-sectional studies $[38,51]$

evidence was downgraded from "low" to "very low" due to a serious risk of bias. The 3 cross-sectional studies $[30,31,81]$ showed either favourable (i.e., longer sleep duration was associated with more physical activity) or null findings. The quality of evidence remained at "low" for the cross-sectional studies.

\section{Quality of life/well-being}

Only 1 study examined the association between sleep duration and quality of life/well-being (Table 8 and Additional file 2: Table S2). This longitudinal study found that short sleep duration at 3 years of age $(<10 \mathrm{~h}$ versus $>11 \mathrm{~h}$ ) was not associated with poor quality of life at $\sim 13$ years of age [82]. The quality of evidence was downgraded from "low" to "very low" because of a serious risk of bias.

\section{Risks/injuries}

Three cross-sectional studies examined the association between sleep duration and risks/injuries in children aged 0-4 years (Table 9 and Additional file 2: Table S2). Koulouglioti et al. [83] reported that children with shorter sleep duration sustained a higher number of medically attended injuries. Likewise, Boto et al. [84] reported that a sleep duration shorter than $8 \mathrm{~h}$ per day was associated with an increased risk of accidental falls. In contrast, Owens et al. [85] did not find an association between sleep duration and injury risk. The quality of evidence remained at "low" for the cross-sectional studies.

\section{Summary of findings}

A high-level summary of findings by health outcome can be found in Table 10. Overall, studies tended to show

Table 5 Association between sleep duration and growth in children aged 0-4 years

\begin{tabular}{lllll}
\hline $\begin{array}{l}\text { No of } \\
\text { studies }\end{array}$ & Design & Quality Assessment & No of & Absolute effect \\
\cline { 2 - 3 } & Risk of bias Inconsistency Indirectness Imprecision & Other & Quality
\end{tabular}

Mean age ranged between 4 months and 17 months. Data were collected cross-sectionally and up to 13 months. Sleep duration was assessed by actigraphy or parent report. Growth was assessed using the maximum stretch technique and using weight above the expected weight for length.

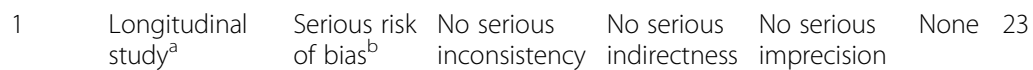

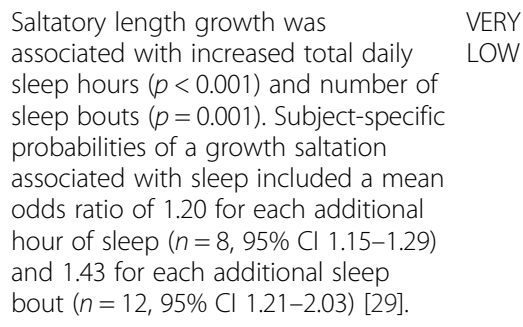

Saltatory length growth was VERY associated with increased total daily LOW sleep hours $(p<0.001)$ and number of sleep bouts $(p=0.001)$. Subject-specific probabilities of a growth saltation associated with sleep included a mean odds ratio of 1.20 for each additional hour of sleep $(n=8,95 \% \mathrm{Cl} 1.15-1.29)$ and 1.43 for each additional sleep bout ( $n=12,95 \%$ Cl 1.21-2.03) [29].

Using actigraphy, sleep duration was VERY associated with weight-to-length ratio LOW $(r=-0.47, p<0.01)$ in girls only. Using the questionnaire, night sleep duration was associated with weight-to-length ratio $(r=-0.26, p<0.05)$ and weight above the expected weight for length $(r=-0.25, p<0.05)$ in the total sample [77].

\footnotetext{
ancludes 1 longitudinal study [29]

bSleep duration was parent-reported with no psychometric properties reported. Therefore, the quality of evidence was downgraded from "low" to "very low" Includes 1 cross-sectional study [77]

${ }^{\mathrm{d} O n l y}$ one study was published, including a convenience sample of infants and showing differences between boys and girls with the use of actigraphy, so the risk of imprecision is high. Therefore, the quality of evidence was downgraded from "low" to "very low". Due to the fact that only two studies were published on sleep duration and growth, a meta-analysis was not possible
} 


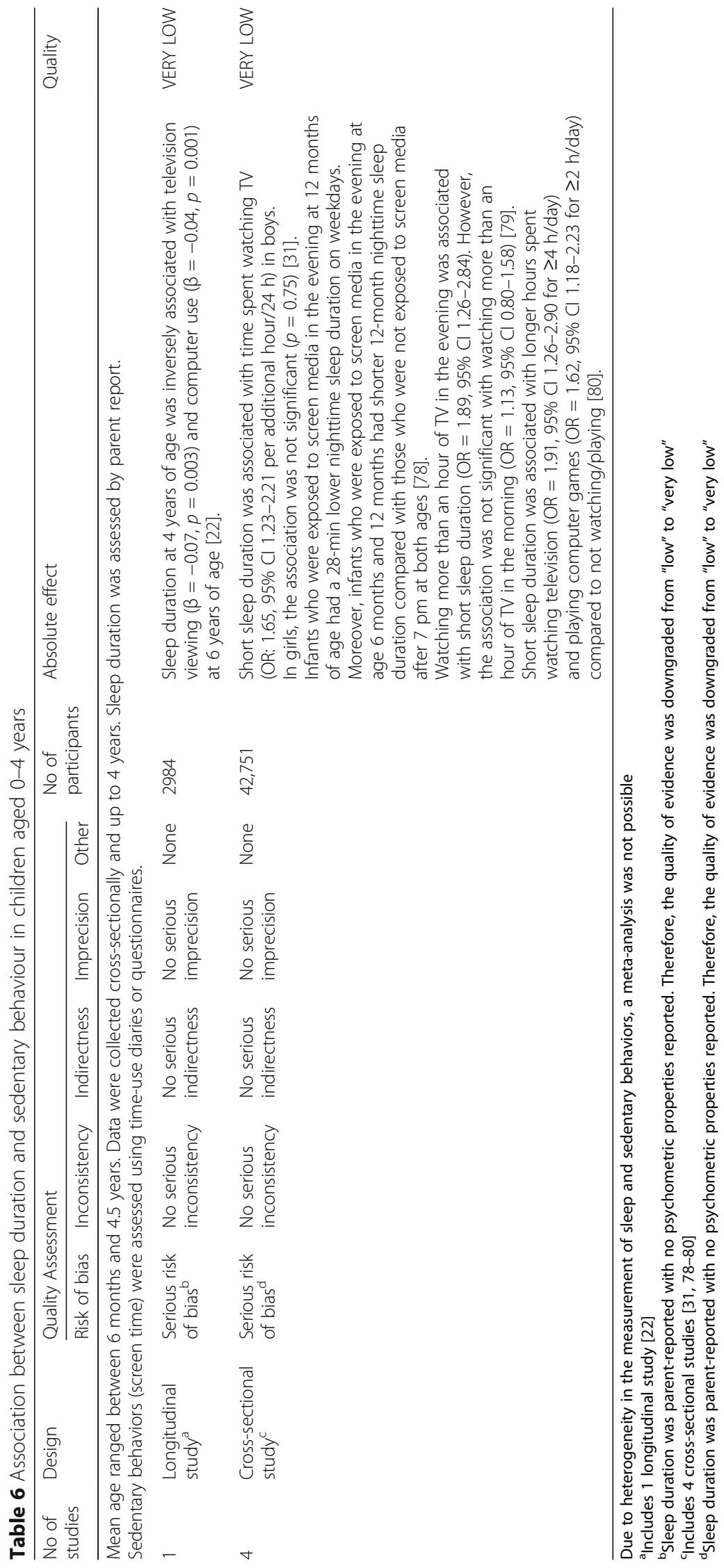


Table 7 Association between sleep duration and physical activity in children aged 0-4 years

\begin{tabular}{llll}
\hline $\begin{array}{l}\text { No of } \\
\text { studies }\end{array}$ & Quality Assessment & No of & Absolute effect \\
\cline { 2 - 3 } & Risk of bias Inconsistency Indirectness Imprecision Other & \\
\hline
\end{tabular}

Mean age ranged between 20 months and 4.5 years. Data were collected cross-sectionally and up to 4 years.

Sleep duration was assessed by parent report. Physical activity was assessed using accelerometers, time-use diaries or questionnaires.

$1 \quad$ Longitudinal Serious risk No serious No serious No serious None 2984 study $^{\mathrm{a}} \quad$ of bias $^{\mathrm{b}}$ inconsistency indirectness imprecision

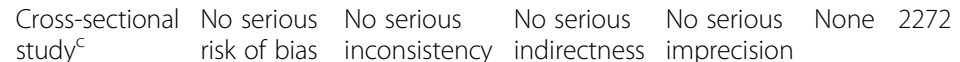

Sleep duration at 4 years of age was not associated with physical activity at 6 years of age $(\beta=-0.02,95 \%$ $\mathrm{Cl}-0.09-0.03)[22]$.

Longer nighttime sleep duration was associated with more physical activity (MVPA min/day: $r=0.19, p=0.012$; activity counts: $r=0.21, p=0.006$ ). In multivariable models, nighttime sleep duration was positively associated with physical activity ( $\beta=0.332, p=0.017)$ [30]. Sleep duration was not associated with physical activity in either boys $(p=0.89)$ or girls $(p=0.41)$ [31].

Total daily sleep duration was positively associated with physical activity in boys only (OR $=1.04,95 \% \mathrm{Cl} 1.02-1.07)$ [81].

Due to heterogeneity in the measurement of sleep and physical activity, a meta-analysis was not possible ancludes 1 longitudinal study [22]

bSleep duration was parent-reported with no psychometric properties reported. Therefore, the quality of evidence was downgraded from "low" to "very low" Includes 3 cross-sectional studies [30, 31, 81]

favourable associations between sleep duration and adiposity (20/31 studies), emotional regulation (13/25 studies), growth (2/2 studies), screen time (5/5 studies), and risks/injuries (2/3 studies). However, no association was found between sleep duration and motor development (only 2 studies) and quality of life (only 1 study), and the evidence was mixed for cognitive development and physical activity indicators. It is difficult to establish the optimal amount of sleep associated with favourable health outcomes based on the available evidence. Most of the evidence was correlational in nature or compared groups with different cut-points for short and long sleep duration. However, longer sleep durations, when compared to shorter sleep durations, were generally associated with better outcomes in the studies synthesized herein, and the pattern of associations did not differ by the age group examined (i.e., infants, toddlers, and preschoolers).

\section{Discussion}

This systematic review synthesized peer-reviewed scientific evidence from 69 articles/studies examining the relationships between sleep duration and key health indicators in children aged $0-4$ years. The overall quality of evidence ranged from "very low" to "high" across study designs and health indicators. Collectively, shorter sleep duration was generally associated with higher adiposity, poorer emotional regulation, impaired growth, more screen time, and higher risk of injuries. However, the evidence was mixed for cognitive development and physical activity, and null findings were reported for motor development and quality of life. Also, no studies

Table 8 Association between sleep duration and quality of life/well-being in children aged 0-4 years

\begin{tabular}{|c|c|c|c|c|c|c|c|c|c|}
\hline \multirow{2}{*}{$\begin{array}{l}\text { No of } \\
\text { studies }\end{array}$} & \multirow[t]{2}{*}{ Design } & \multicolumn{5}{|c|}{ Quality Assessment } & \multirow{2}{*}{$\begin{array}{l}\text { No of } \\
\text { participants }\end{array}$} & \multirow[t]{2}{*}{ Absolute effect } & \multirow[t]{2}{*}{ Quality } \\
\hline & & Risk of bias & Inconsistency & Indirectness & Imprecision & Other & & & \\
\hline \multicolumn{10}{|c|}{$\begin{array}{l}\text { Children were } 3 \text { years of age and followed until first-year junior high school (approximately } 13 \text { years old). Data were collected longitudinally } \\
\text { (approximately a } 10 \text {-year follow-up period). Sleep duration was assessed by parent report. Quality of life was assessed using the } \\
\text { Dartmouth Primary Care Cooperative Project (COOP) charts. }\end{array}$} \\
\hline 1 & $\begin{array}{l}\text { Longitudinal } \\
\text { study }^{a}\end{array}$ & $\begin{array}{l}\text { Serious risk } \\
\text { of bias }^{b}\end{array}$ & $\begin{array}{l}\text { No serious } \\
\text { inconsistency }\end{array}$ & $\begin{array}{l}\text { No serious } \\
\text { indirectness }\end{array}$ & $\begin{array}{l}\text { No serious } \\
\text { imprecision }\end{array}$ & None & 9674 & $\begin{array}{l}\text { Short sleep duration at } 3 \text { years of age } \\
(<10 \mathrm{~h} \text { vs. }>11 \mathrm{~h}) \text { was not associated } \\
\text { with quality of life at age } \sim 13 \text { years } \\
(\mathrm{OR}=1.15,95 \% \mathrm{Cl} 0.99-1.33, p=0.06) \\
{[82] .}\end{array}$ & VERY LOW \\
\hline
\end{tabular}

Due to the fact that only one study was published on sleep duration and quality of life/well-being, a meta-analysis was not possible ancludes 1 longitudinal study [82]

bSleep duration was parent-reported with no psychometric properties reported. Therefore, the quality of evidence was downgraded from "low" to "very low" 


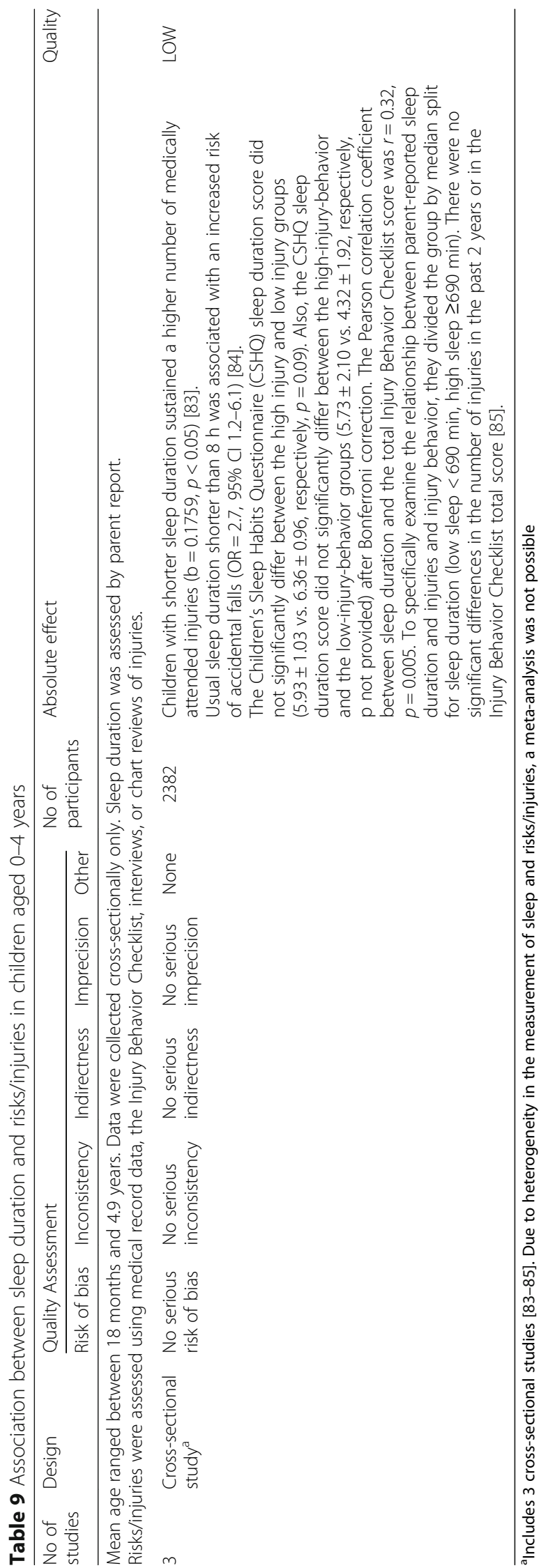


Table 10 High-level summary of findings by health indicator

\begin{tabular}{|c|c|c|c|}
\hline Health Indicator & \# of studies & Quality of Evidence & Summary of Findings \\
\hline \multicolumn{4}{|l|}{ Critical } \\
\hline Adiposity & 31 & Low & $\begin{array}{l}N=20 \text { studies reported a significant association between shorter sleep duration } \\
\text { and adiposity. } \\
N=9 \text { studies reported null findings. } \\
N=2 \text { studies reported a significant association between longer sleep duration } \\
\text { and adiposity. }\end{array}$ \\
\hline $\begin{array}{l}\text { Emotional } \\
\text { Regulation }\end{array}$ & 25 & Very Low to High & $\begin{array}{l}N=13 \text { studies reported a significant association between shorter sleep duration } \\
\text { and poorer emotional regulation. } \\
N=10 \text { studies reported null findings. } \\
N=2 \text { studies reported a significant association between longer sleep duration } \\
\text { and poorer emotional regulation. }\end{array}$ \\
\hline $\begin{array}{l}\text { Cognitive } \\
\text { Development }\end{array}$ & 16 & Low to High & $\begin{array}{l}N=6 \text { studies reported a significant association between shorter sleep duration } \\
\text { and poorer cognitive function. } \\
N=8 \text { reported null findings. } \\
N=2 \text { study reported a significant association between longer sleep duration } \\
\text { and poorer cognitive function. }\end{array}$ \\
\hline $\begin{array}{l}\text { Motor } \\
\text { Development }\end{array}$ & 2 & Low & $N=2$ studies reported null findings. \\
\hline Growth & 2 & Very Low & $N=2$ studies reported better growth with longer sleep duration. \\
\hline \multicolumn{4}{|l|}{ Important } \\
\hline Sedentary Behavior & 5 & Very Low & $\begin{array}{l}N=5 \text { studies reported shorter sleep duration was associated with more } \\
\text { screen time. }\end{array}$ \\
\hline Physical Activity & 4 & Low to Very Low & $\begin{array}{l}N=2 \text { studies reported longer sleep duration was associated with more } \\
\text { physical activity. } \\
N=2 \text { studies reported null findings. }\end{array}$ \\
\hline Risks/Injuries & 3 & Low & $\begin{array}{l}N=2 \text { studies reported a higher risk of injuries with shorter sleep duration. } \\
N=1 \text { study reported null findings. }\end{array}$ \\
\hline $\begin{array}{l}\text { Quality of } \\
\text { Life/Well-Being }\end{array}$ & 1 & Very Low & $N=1$ study reported null findings. \\
\hline $\begin{array}{l}\text { Cardio-Metabolic } \\
\text { Health }\end{array}$ & 0 & N/A & N/A \\
\hline
\end{tabular}

The number of studies is more than $N=69$ because some papers had more than one outcome measure and/or study design

examined the association between sleep duration and cardiometabolic biomarkers in this population. Overall, this comprehensive assessment of available evidence should encourage efforts aimed at promoting the importance of sleep duration for overall health in children aged $0-4$ years.

Adiposity ( $n=31$ studies) and emotional regulation ( $n=25$ studies) were the health indicators with the highest number of studies in the present systematic review. This is in agreement with our previous systematic review examining the associations between sleep duration and health indicators in school-aged children and youth [2]. However, the findings from these two health indicators in the current paper are more mixed than those found in the children and youth review. Potential reasons to explain this difference include: (1) differences in measurement tools used to assess sleep duration and health outcomes; (2) differences in confounding factors; (3) differences in development stages; (4) differences in the robustness of study designs; and (5) the likelihood that it is more difficult to find associations with adverse health indicators in a younger and healthier population of children, as the outcomes explored in this review are likely to manifest over time if short sleep duration is prolonged .

Many tools have been used to assess emotional regulation in the studies reviewed herein. These included videorecording, various questionnaires, and even cortisol response. It is debatable whether cortisol awakening response (CAR) is an emotional regulation indicator, but it fit our inclusion/exclusion criteria as a stress marker. The non-randomized intervention that examined CAR after sleep restriction [44] showed that CAR was robust after nighttime sleep, diminished after sleep restriction, and was smaller but still distinct after morning and afternoon naps. Although the authors indicated in their article that reduced CAR after shortened sleep suggests a decreased ability to deal with environmental stressors, this viewpoint is not unanimous in the scientific community.

Findings of studies included in the present systematic review are consistent with current sleep duration recommendations, and we are not advocating that they should be changed. However, based on the results of our review-which gathered the best evidence available in 
this field of research-it is clear that, currently, the evidence being used to inform sleep duration recommendations in the early years is weak, suggesting that expert opinion is needed until more and better research is conducted. There is an urgent need for higher-quality studies that can help to better inform recommendations for sleep duration in this population. For example, the available evidence relies heavily on cross-sectional studies that use parent-reported sleep durations. Multiple age groups were also grouped together, despite obvious differences in development. Most importantly, the current evidence is largely correlational in nature, and there is a clear need for dose-response curves with multiple time points of sleep duration that can provide a better idea of optimal sleep duration ranges. In an experimental context, this means examining how health indicators change in response to sleep restriction/extension interventions. In observational studies, this means comparing several categories of sleep duration in relation to health indicators rather than using continuous data in order to have a better sense of dose-response gradient. Ideally, results would be reported for narrower age groups that are aligned with the current sleep duration recommendations (i.e., newborns [0-3 months], infants [4-11 months], toddlers [ $1-2$ years], preschoolers [3-5 years]); development progresses rapidly in the early years and many factors can confound the associations (e.g., growth, eating habits, environment, locomotion).

The National Sleep Foundation in the USA recommends that in each 24-h cycle, newborns (0-3 months) obtain 14-17 h of sleep, infants (4-11 months) obtain $12-15 \mathrm{~h}$ of sleep, toddlers (1-2 years) obtain $11-14 \mathrm{~h}$ of sleep, and preschoolers (3-5 years) obtain $10-13 \mathrm{~h}$ of sleep [9]. The American Academy of Sleep Medicine issued similar recommendations in 2016 [10]. To develop their guidelines, both organizations relied on a multidisciplinary expert panel to evaluate the latest scientific evidence, including a consensus and voting process. The present systematic review will also help to inform the Canadian 24-Hour Movement Guidelines for the Early Years (0-4 Years): An Integration of Physical Activity, Sedentary Behaviour, and Sleep [86].

Existing sleep duration recommendations provide ranges and imply that a U-shaped association exists between sleep duration and health outcomes, with one side of the "U" representing short sleep duration and the other side representing long sleep duration. It is increasingly recognized that the two sides of this U-shape have different health impacts [87]. While insufficient sleep is a stressor for the metabolism and is consistently associated with adverse health outcomes, excessively long sleep duration may interfere with children's exploration of their physical and social environment and thereby possibly impede their optimal development [88]. Thus, it is logical for public health sleep duration guidelines to recommend a range to represent "healthy" or "optimal" sleep durations rather than a threshold value.

The present systematic review focused on sleep duration only. However, many other important factors beyond sleep quantity should be considered in the development of sleep recommendations, including aspects of sleep quality such as sleep efficiency (i.e., proportion of the sleep opportunity actually spent in sleep), timing (i.e., bedtime/wake-up times and naps), sleep architecture (i.e., sleep stages), consistency (i.e., day-to-day variability, seasonal changes), and sleep consolidation (i.e., organization of sleep across the night). The National Sleep Foundation recently published evidencebased recommendations and guidance to the public regarding indicators of good sleep quality across the lifespan [89]. Overall, the panel members agreed that most sleep continuity variables (e.g., sleep latency, number of awakenings $>5$ min, wake after sleep onset, and sleep efficiency) were appropriate indicators of good sleep quality. However, there was less or no consensus regarding sleep architecture or nap-related variables as indicators of good sleep quality.

Sleep duration in the early years is generally comprised of both daytime and nighttime sleep. However, it has been reported that daytime sleep and nighttime sleep may not have the same effects on health, with positive effects of sleep duration suggested to relate to the stage in sleep transition from polyphasic to monophasic sleep (the stage at which naps cease) [90]. The same systematic review also concluded that beyond the age of 2 years, napping is associated with later sleep onset at night as well as reductions in both sleep quality and duration, suggesting that clinicians should investigate napping patterns in children who present with sleep problems [90]. As discussed extensively in previous papers, many healthy sleep practices can help to achieve ageappropriate amounts of sleep, including having a consistent bedtime routine and removing screens from children's bedrooms $[88,91]$.

It is also well-known that parent-reported sleep duration overestimates actual sleep duration compared with objective measures [92]. This can have implications for sleep duration recommendations if future studies rely more heavily on objective assessments of sleep, because this will require extrapolation of objectively measured sleep durations to real-world conditions. Most of the studies synthesized in the present work utilized subjective measures of sleep with no psychometric properties, and results may have more ecological validity.

A number of limitations and research gaps have been highlighted in the discussion section already. However, other limitations of the present systematic review should be mentioned. First, the high level of heterogeneity 
across studies precluded conducting meta-analyses, and all studies were weighted equally. Second, the present systematic review included only articles published in English or French, meaning any relevant studies published in other languages were excluded. Third, the risk of publication bias (i.e., an over-representation of studies with significant findings) is always a possibility in science. Finally, many studies did not adjust for important confounding factors (e.g., diet when examining adiposity as an outcome measure), thereby impacting our confidence in the estimates of effect for the outcome measures.

\section{Conclusions}

The present article was the first to systematically examine the associations between sleep duration and a broad range of key health indicators in children aged 0-4 years. We provide support for previous evidence showing that shorter sleep duration is associated with adverse health indicators in some areas of physical and mental health; however, the synthesized evidence relies heavily on cross-sectional study designs and parent-reported sleep durations, and combines multiple ages together despite clear differences in development. To better inform sleep recommendations, scientists should conduct and publish higher-quality studies in this population to have a better idea of dose-response relationships. Robust sleep guidelines should be based on the best available evidence, expert consensus, stakeholder consultation, and consideration of values and preferences, applicability, feasibility, resource use, and equity [86]. There is a clear need for more and better studies in this young age group, which is an important time for growth and development.

\section{Additional files}

Additional file 1: Table S1. Search strategy for the systematic review. (DOC $175 \mathrm{~kb}$ )

Additional file 2: Table S2. Summary of studies included in the systematic review sorted by (whenever possible) outcome indicator, study design, age group, and sleep assessment

(objective, then subjective). (DOC $254 \mathrm{~kb}$ )

\begin{abstract}
Abbreviations
CAR: Cortisol awakening response; CENTRAL: Cochrane Central Register of Controlled Trials; GRADE: Grading of Recommendations Assessment, Development and Evaluation; PICOS: Participants, interventions, comparisons, outcomes, and study design; PRISMA: Preferred Reporting Items for Systematic Reviews and Meta-Analyses; PROSPERO: International Prospective Register of Systematic Reviews
\end{abstract}

\section{Acknowledgements}

We would like to thank Alejandra Jaramillo, Linda Slater, Holly Livock, Laura Callender, and Sheniz Eryuzlu for providing help with the screening process and the methodology.

\section{Funding}

This study has been made possible through funding from the Public Health Agency of Canada, the Canadian Society for Exercise Physiology, and the Healthy Active Living and Obesity Research Group at the Children's Hospital of Eastern Ontario Research Institute. Publication charges for this article have been funded by the Public Health Agency of Canada. VC was supported by a Canadian Institutes of Health Research (CIHR) New Investigator Salary Award.

Availability of data and materials

Not applicable

\section{About this supplement}

This article has been published as part of BMC Public Health Volume 17 Supplement 5, 2017: 24-Hour Movement Guidelines for the Early Years: An Integration of Physical Activity, Sedentary Behaviour, and Sleep. The full contents of the supplement are available online at https://bmcpublichealth biomedcentral.com/articles/supplements/volume-17-supplement-5.

\section{Authors' contributions}

JPC, CEG, VJP, VC, RG, CSB, JEM, SA, MS, and MST participated in the conception of the article. JPC, CEG, and SA screened the articles. JPC extracted the data and SA checked the extracted data. JPC wrote the first version of the manuscript. All authors participated in the revisions of the manuscript, and read and approved the final manuscript.

Ethics approval and consent to participate

Not applicable

\section{Consent for publication}

Not applicable

\section{Competing interests}

The authors declare that they have no competing interests.

\section{Publisher's Note}

Springer Nature remains neutral with regard to jurisdictional claims in published maps and institutional affiliations.

\section{Author details}

'Healthy Active Living and Obesity Research Group, Children's Hospital of Eastern Ontario Research Institute, 401 Smyth Road, Ottawa, ON K1H 8L1,

Canada. ${ }^{2}$ Faculty of Physical Education and Recreation, University of Alberta, Edmonton, AB T6G 2H9, Canada. ${ }^{3}$ Department of Psychiatry, Faculty of Medicine, McGill University, Montreal, QC H3A 1A1, Canada. ${ }^{4}$ Division of Paediatric Medicine, Department of Paediatrics, The Hospital for Sick Children, University of Toronto, Toronto, ON M5G 1X8, Canada. ${ }^{5}$ Department of Pediatrics, Faculty of Medicine \& Dentistry, University of Alberta, Edmonton, AB T6G 1C9, Canada.

Published: 20 November 2017

\section{References}

1. Institute of Medicine (US) Committee on Sleep Medicine and Research. In: Colten HR, Altevogt BM, editors. Sleep disorders and sleep deprivation: an unmet public health problem. Washington, DC: The National Academies Press; 2006

2. Chaput JP, Gray CE, Poitras VJ, Carson V, Gruber R, Olds T, et al. Systematic review of the relationships between sleep duration and health indicators in school-aged children and youth. Appl Physiol Nutr Metab. 2016;41(Suppl 3): 266-82.

3. Gruber R, Carrey N, Weiss SK, Frappier JY, Rourke L, Brouillette RT, et al. Position statement on pediatric sleep for psychiatrists. J Can Acad Child Adolesc Psychiatry. 2014;23:174-95.

4. McLaughlin Crabtree V, Williams NA. Normal sleep in children and adolescents. Child Adolesc Psychiatr Clin N Am. 2009;18:799-811.

5. Davis KF, Parker KP, Montgomery GL. Sleep in infants and young children: part one: normal sleep. J Pediatr Health Care. 2004;18:65-71.

6. Sheldon SH. Sleep in infants and children. In: Lee-Chiong TL, Sateia MJ, Carskadon MA, editors. Sleep Medicine. Philadelphia: Hanley and Belfus Inc.; 2002. p. 99-103.

7. Iglowstein I, Jenni OG, Molinari L, Largo RH. Sleep duration from infancy to adolescence: reference values and generational trends. Pediatrics. 2003;111:302-7.

8. Galland BC, Taylor BJ, Elder DE, Herbison P. Normal sleep patterns in infants and children: a systematic review of observational studies. Sleep Med Rev. 2012;16:213-22. 
9. Hirshkowitz M, Whiton K, Albert SM, Alessi C, Bruni O, DonCarlos L, et al. National Sleep Foundation's updated sleep duration recommendations: final report. Sleep Health. 2015;1:233-43.

10. Paruthi S, Brooks L, D'Ambrosio C, Hall WA, Kotagal S, Lloyd RM, et al. Recommended amount of sleep for pediatric populations: a consensus statement of the American Academy of Sleep Medicine. J Clin Sleep Med. 2016;12:785-6.

11. Matricciani L, Olds TS, Blunden S, Rigney G, Williams MT. Never enough sleep: a brief history of sleep recommendations for children. Pediatrics. 2012;129:548-56

12. Matricciani L, Blunden S, Rigney G, Williams MT, Olds TS. Children's sleep needs: is there sufficient evidence to recommend optimal sleep for children? Sleep. 2013;36:527-34.

13. Moher D, Liberati A, Tetzlaff J, Altman DG. Preferred reporting items for systematic reviews and meta-analyses: the PRISMA statement. Ann Intern Med. 2009;151:264-9.

14. Schardt C, Adams MB, Owens T, Keitz S, Fontelo P. Utilization of the PICO framework to improve searching PubMed for clinical questions. BMC Med Inform Decis Mak. 2007;7:16.

15. Higgins J, Green S. Cochrane handbook for systematic reviews of interventions, version 5.1.0. The Cochrane Collaboration. 2010. http://www. cochrane-handbook.org. Accessed 13 June 2017.

16. Guyatt GH, Oxman AD, Vist G, Kunz R, Brozek J, Alonso-Coello P, et al. GRADE guidelines: 4. Rating the quality of evidence - study limitations (risk of bias). J Clin Epidemiol. 2011;64:407-15.

17. Agras WS, Hammer LD, McNicholas F, Kraemer HC. Risk factors for childhood overweight: a prospective study from birth to 9.5 years. J Pediatr. 2004;145:20-5

18. Reilly JJ, Armstrong J, Dorosty AR, Emmett PM, Ness A, Rogers I, et al. Early life risk factors for obesity in childhood: cohort study. BMJ. 2005;330:1357.

19. Bonuck K, Chervin RD, Howe LD. Sleep-disordered breathing, sleep duration, and childhood overweight: a longitudinal cohort study. J Pediatr. 2015;166: 632-9.

20. Touchette E, Petit D, Tremblay RE, Boivin M, Falissard B, Genolini C, et al. Associations between sleep duration patterns and overweight/obesity at age 6. Sleep. 2008;31:1507-14.

21. Speirs KE, Liechty JM, CF W. Strong kids research team. Sleep, but not other daily routines, mediates the association between maternal employment and BMI for preschool children. Sleep Med. 2014;15:1590-3.

22. Magee C, Caputi P, Iverson D. Lack of sleep could increase obesity in children and too much television could be partly to blame. Acta Paediatr. 2014;103:e27-31.

23. Diethelm K, Bolzenius K, Cheng G, Remer T, Buyken AE. Longitudinal associations between reported sleep duration in early childhood and the development of body mass index, fat mass index and fat free mass index until age 7. Int J Pediatr Obes. 2011;6:e114-23.

24. Carter PJ, Taylor BJ, Williams SM, Taylor RW. Longitudinal analysis of sleep in relation to $\mathrm{BMI}$ and body fat in children: the FLAME study. BMJ. 2011;342: d2712.

25. Butte NF, Puyau MR, Wilson TA, Liu YL, Wong WW, Adolph AL, et al. Role of physical activity and sleep duration in growth and body composition of preschool-aged children. Pediatr Obes. 2016;24:1328-35.

26. Sharf RJ, DeBoer MD. Sleep timing and longitudinal weight gain in 4- and 5-year-old children. Pediatr Obes. 2014;10:141-8.

27. Hiscock H, Scalzo K, Canterford L, Wake M. Sleep duration and body mass index in 0-7-year olds. Arch Dis Child. 2011;96:735-9.

28. Klingenberg L, Christensen LB, Hjorth MF, Zangenberg S, Chaput JP, Sjodin $A$, et al. No relation between sleep duration and adiposity indicators in 9-36 months old children: the SKOT cohort. Pediatr Obes. 2012;8:E14-8.

29. Lampl M, Johnson ML. Infant growth in length follows prolonged sleep and increased naps. Sleep. 2011;34:641-50.

30. Hager ER, Calamaro CJ, Bentley LM, Hurley KM, Wang Y, Black MM. Nighttime sleep duration and sleep behaviors among toddlers from lowincome families: associations with obesogenic behaviors and obesity and the role of parenting. Child Obes. 2016;12:392-400.

31. Plancoulaine S, Lioret $\mathrm{S}$, Regnault N, Heude B, Charles MA, Eden MotherChild Cohort Study Group. Gender-specific factors associated with shorter sleep duration at age 3 years. J Sleep Res. 2015;24:610-20.

32. Dev DA, McBride BA, Fiese BH, Jones BL, Cho H. Risk factors for overweight/ obesity in preschool children: an ecological approach. Child Obes. 2013;9: 399-408.
33. Jones BL, Fiese BH, STRONG Kids Team. Parent routines, child routines, and family demographics associated with obesity in parents and preschool-aged children. Front Psychol. 2014;5:374.

34. Jiang F, Zhu S, Yan C, Jin X, Bandla H, Shen X. Sleep and obesity in preschool children. J Pediatr. 2009;154:814-8.

35. Sijtsma A, Koller M, Sauer PJ, Corpeleijn E. Television, sleep, outdoor play and BMI in young children: the GECKO Drenthe cohort. Eur J Pediatr. 2015;174:631-9.

36. Watanabe E, Lee JS, Kawakubo K. Associations of maternal employment and three-generation families with pre-school children's overweight and obesity in Japan. Int J Obes. 2011;35:945-52.

37. Dieu HT, Dibley MJ, Sibbritt D, Hanh TT. Prevalence of overweight and obesity in preschool children and associated socio-demographic factors in Ho Chi Minh City, Vietnam. Int J Pediatr Obes. 2007;7:40-50.

38. Gibson R, Elder D, Gander P. Actigraphic sleep and development progress of one-year-old infants. Sleep Biol Rhythms. 2012;10:77-83.

39. Fisher A, McDonald L, van Jaarsveld CHM, Llewellyn C, Fildes A, Schrempft S, et al. Sleep and energy intake in early childhood. Int J Obes. 2014;38:926-9.

40. Cardon G, De Bourdeaudhuij I, lotova V, Latomme J, Socha P, Koletzko B, et al. Health related behaviours in normal weight and overweight preschoolers of a large pan-European sample: the ToyBox-Study. PLoS One. 2016;11: e0150580.

41. Kuzik N, Carson V. The association between physical activity, sedentary behavior, sleep, and body mass index z-scores in different settings among toddlers and preschoolers. BMC Pediatr. 2016;16:100.

42. Miller AL, Seifer R, Crossin R, Lebourgeois MK. Toddler's self-regulation strategies in a challenge context are nap-dependent. J Sleep Res. 2015;24:279-87.

43. Berger RH, Miller AL, Seifer R, Cares SR, Lebourgeois MK. Acute sleep restriction effects on emotion responses in 30- to 36-month-old children. J Sleep Res. 2012;21:235-46.

44. Gribbin CE, Watamura SE, Cairns A, Harsh JR, LeBourgeois K. The cortisol awakening response (CAR) in 2- to 4-year old children: effects of acute nighttime sleep restriction, wake time, and daytime napping. Dev Psychobiol. 2012;54:412-22.

45. Jansen PW, Saridjan NS, Hofman A, Jaddoe WWV, Verhulst FC, Tiemeier H. Does disturbed sleeping precede symptoms of anxiety or depression in toddlers? The generation R study. Psychosom Med. 2011:73:242-9.

46. Bouvette-Turcot AA, Pluess M, Bernier A, Pennestri MH, Levitan R, Sokolowski MB, et al. Effects of genotype and sleep on temperament. Pediatrics. 2015;136:e914-21.

47. Saenz J, Yaugher A, Alexander GM. Sleep in infancy predicts gender specific social-emotional problems in toddlers. Front Pediatr. 2015;3:42.

48. Kobayaski K, Yorifujji T, Yamakawa M, Oka M, Inoue S, Yoshinaga H, et al. Poor toddler-age sleep schedules predict school-age behavioral disorders in a longitudinal survey. Brain and Development. 2015:37:572-8.

49. Shinohara $\mathrm{H}$, Kodama $\mathrm{H}$. Relationship between duration of crying/fussy behavior and actigraphic sleep measures in early infancy. Early Hum Dev. 2012;88:847-52.

50. Kaley F, Reid V, Flynn E. Investigating the biographic, social and temperamental correlates of young infants' sleeping, crying and feeding routines. Infant Behav Dev. 2012;35:596-605.

51. Mindell JA, Lee C. Sleep, mood and development in infants. Infant Behav Dev. 2015;41:102-7.

52. Scher A, Epstein R, Sadeh A, Tirosh E, Lavie P. Toddlers' sleep and temperament: reporting bias or a valid link? A research note. J Child Psychol Psychiatry. 1992;33:1249-54.

53. Hysing M, Sivertsen B, Garthus-Niegel S, Eberhard-Gran M. Pediatric sleep problems and social-emotional problems. A population-based study. Infant Behav Dev. 2016;42:111-8.

54. Lavigne JV, Arend R, Rosenbaum D, Smith A, Weissbluth M, Binns HJ, et al Sleep and behavior problems among preschoolers. J Dev Behav Pediatr. 1999:20:164-9.

55. Keefe-Cooperman K, Brady-Amoon P. Preschooler sleep patterns related to cognitive and adaptive functioning. Early Educ Dev. 2014;25:859-74.

56. Scharf RJ, Demmer RT, Silver EJ, Stein REK. Nighttime sleep duration and externalizing behaviors of preschool children. J Dev Behav Pediatr. 2013;34:384-91.

57. Vaughn BE, Elmore-Staton L, Shin N, El-Sheikh M. Sleep as a support for social competence, peer relations, and cognitive functioning in preschool children. Behav Sleep Med. 2015;13:92-106.

58. Scher A, Tirosh E, Lavie P. The relationship between sleep and temperament revisited: evidence for 12-months-olds: a research note. J Child Psychol Psychiatry. 1998;39:785-8. 
59. Gibson R, Gander P, Elder D. Factors differentiating infants identified by parents as problem sleepers, and those that are not. Sleep Biol Rhythms. 2012;10:46-52

60. Komada Y, Abe T, Okajima I, Asaoka S, Matsuura N, Usui A, et al. Short sleep duration and irregular bedtime are associated with increased behavioral problems among Japanese preschool-age children. J Exp Med. 2011;224: 127-36.

61. Molfese VJ, Rudasill KM, Prokasky A, Champagne C, Holmes M, Molfese DL, et al. Relations between toddler sleep characteristics, sleep problems, and temperament. Dev Neuropsychol. 2015;40:138-54.

62. Yokomaku A, Misao K, Omoto F, Yamagishi R, Tanaka K, Takada K, et al. A study of the association between sleep habits and problematic behaviors in preschool children. Chronobiol Int. 2008:25:549-64.

63. Spruyt K, Aitken RJ, So K, Charlton T, Adamson M, RSC H. Relationship between sleep/wake patterns, temperament and overall development in term infants over the first year of life. Early Hum Dev. 2008;84:289-96.

64. Liu Z, Wang G, Geng L, Luo J, Li N, Owens J. Sleep patterns, sleep disturbances, and associated factors among Chinese urban kindergarten children. Behav Sleep Med. 2016;14:100-17.

65. Giganti F, Arzilli C, Conte F, Toselli M, Viggiano MP, Ficca G. The effect of a daytime nap on priming and recognition tasks in preschool children. Sleep. 2014;37:1087-93.

66. Bernier A, Beauchamp MH, Bouvette-Turcot AA, Carlson SM, Carrier J. Sleep and cognition in preschool years: specific links to executive functioning. Child Dev. 2013;84:1542-53.

67. Bernier A, Carlson SM, Bordeleau S, Carrier J. Relations between physiological and cognitive regulatory systems: infant sleep regulation and subsequent executive functioning. Child Dev. 2010;81:1739-52.

68. Horvath K, Plunkett K. Frequent daytime naps predict vocabulary growth in early childhood. J Child Psychol Psychiatry. 2016:57:1008-17.

69. Jung E, Molfese VJ, Beswick J, Jacobi-Vessels J, Molnar A. Growth of cognitive skills in preschoolers: impact of sleep habits and learning-related behaviors. Early Educ Dev. 2009;20:713-31

70. Konrad C, Herbert JS, Schneider S, Seehagen S. The relationship between prior night's sleep and measures of infant imitation. Dev Psychobiol. 2016; 58:450-61.

71. Scher A. Infant sleep at 10 months of age as a window to cognitive development. Early Hum Dev. 2005:81:289-92.

72. Lukowski AF, Milojevich HM. Sleeping like a baby: examining relations between habitual infant sleep, recall memory, and generalization across cues at 10 months. Infant Behav Dev. 2013:36:369-76.

73. Hoyniak CP, Petersen IT, McQuillan ME, Staples AD, Bates JE. Less efficient neural processing related to irregular sleep and less sustained attention in toddlers. Dev Neuropsychol. 2015;40:155-66.

74. Lam JC, Mahone EM, Mason T, Scharf SM. The effects of napping on cognitive function in preschoolers. J Dev Behav Pediatr. 2011;32:90-7.

75. Scott N, Blair PS, Emond AM, Fleming PJ, Humphreys JS, Henderson J, et al. Sleep patterns in children with ADHD: a population-based cohort study from birth to 11 years. J Sleep Res. 2013;22:121-8.

76. Nathanson Al, Fries PT. Television exposure, sleep time, and neuropsychological function among preschoolers. Media Psychol. 2014;17:237-61.

77. Tikotzky L, De Marcas G, Har-Toov J, Dollberg S, Bar-Haim Y, Sadeh A. Sleep and physical growth in infants during the first 6 months. J Sleep Res. 2010; 19:103-10.

78. Vijakkhana N, Wilaisakditipakorn T, Ruedeekhajorn K, Pruksananonda C, Chonchaiya W. Evening media exposure reduces night-time sleep. Acta Paediatr. 2015;104:306-12.

79. McDonald L, Wardle J, Llewellyn $\mathrm{CH}$, van Jaarsveld $\mathrm{CH}$, Fisher A. Predictors of shorter sleep in early childhood. Sleep Med. 2014;15:536-40.

80. Ikeda M, Kaneita Y, Kondo S, Itani O, Ohida T. Epidemiological study of sleep habits among four-and-a-half-year-old children in Japan. Sleep Med. 2012; 13:787-94.

81. Hinkley T, Salmon J, Okely AD, Hesketh K, Crawford D. Correlates of preschool children's physical activity. Am J Prev Med. 2012;42:159-67.

82. Wang $H$, Sekine $M$, Chen $X$, Yamagami T, Kagamimori S. Lifestyle at 3 years of age and quality of life (QOL) in first-year junior high school students in Japan: results of the Toyama Birth Cohort Study. Qual Life Res. 2008;17:257-65.

83. Koulouglioti $\mathrm{C}$, Cole R, Kitzman $\mathrm{H}$. Inadequate sleep and unintentional injuries in young children. Public Health Nurs. 2008;25:106-14.

84. Boto LR, Crispim JN, de Melo IS, Juvandes C, Rodrigues T, Azeredo P, et al. Sleep deprivation and accidental fall risk in children. Sleep Med. 2012;13:88-95.
85. Owens JA, Fernando S, Mc Guinn M. Sleep disturbance and injury risk in young children. Behav Sleep Med. 2005;3:18-31.

86. Tremblay MS, Carson V, Chaput JP, Adamo KB, Aubert S, Choquette L, et al. Canadian 24-hour movement guidelines for the early years (0-4 years): an integration of physical activity, sedentary behaviour, and sleep. 2017;17(5) [in press].

87. Knutson KL, Turek FW. The U-shaped association between sleep and health: the 2 peaks do not mean the same thing. Sleep. 2006;29:878-9.

88. Allen SL, Howlett MD, Coulombe JA, Corkum PV. ABCs of SLEEPING: a review of the evidence behind pediatric sleep practice recommendations. Sleep Med Rev. 2016:29:1-14.

89. Ohayon M, Wickwire EM, Hirshkowitz M, Albert SM, Avidan A, Daly FJ, et al. National Sleep Foundation's sleep quality recommendations: first report. Sleep Health. 2017;3:6-19.

90. Thorpe K, Staton S, Sawyer E, Pattinson C, Haden C, Smith S. Napping, development and health from 0 to 5 years: a systematic review. Arch Dis Child. 2015:100:615-22.

91. Mindell JA, Li AM, Sadeh A, Kwon R, Goh DY. Bedtime routines for young children: a dose-dependent association with sleep outcomes. Sleep. 2015; 38:717-22.

92. Girschik J, Fritschi L, Heyworth J, Waters F. Validation of self-reported sleep against actigraphy. J Epidemiol. 2012:5:462-8.

\section{Submit your next manuscript to BioMed Central and we will help you at every step:}

- We accept pre-submission inquiries

- Our selector tool helps you to find the most relevant journal

- We provide round the clock customer support

- Convenient online submission

- Thorough peer review

- Inclusion in PubMed and all major indexing services

- Maximum visibility for your research

Submit your manuscript at www.biomedcentral.com/submit
) Biomed Central 